\title{
PARA UNA RECONSIDERACIÓN DEL LEGADO DE RAMÓN Y CAJAL A LAS NEUROCIENCIAS
}

\author{
Asier Arias Domínguez \\ Facultad de Filosofía, Universidad Complutense de Madrid \\ asier.arias.d@gmail.com \\ ORCID iD: https://orcid.org/0000-0002-2338-3206
}

Recibido: 21 noviembre 2016; Aprobado: 18 diciembre 2017.

Cómo citar este artículo/Citation: Arias Domínguez, Asier (2018), "Para una reconsideración del legado de Ramón y Cajal a las neurociencias", Asclepio, 70 (1): p213. https://doi.org/10.3989/asclepio.2018.06

RESUMEN: Entre 1887 y 1897 Santiago Ramón y Cajal realizó una serie de estudios micrográficos que jalonarían el debate acerca de la estructura y la fisiología del sistema nervioso al suministrar substrato empírico y guía heurística al marco teórico dentro del cual serían las mismas investigadas en lo sucesivo. El significado del trabajo realizado por Cajal en ese decenio no puede ponderarse sin un serio intento de establecer los pertinentes vínculos entre el mismo, sus antecedentes y su contexto contemporáneo. A tal fin, los apartados primero y segundo abordan el contexto científico en que Cajal elaborara en el periodo indicado la teoría neuronal y la ley de la polarización dinámica, prestando atención a planteamientos convergentes y divergentes de contemporáneos y antecesores. El tercero, por su parte, se dedica a la discusión del marco metodológico de la formulación de las señaladas aportaciones, soslayando recientes conatos de polémica historiográfica en torno a la paternidad de las mismas e incidiendo en que el núcleo del legado de Cajal no ha de buscarse en discusiones de esta naturaleza, sino en el amplio cuerpo de observaciones que recogiera y, muy particularmente, en la profusión de hipótesis mediante las cuales tratara de incardinarlo cabalmente en los marcos teóricos sancionados en ciencias biológicas.

PALABRAS CLAVE: Ramón y Cajal; teoría neuronal; ley de la polarización dinámica; neurona; neurohistología.

\section{A RECONSIDERATION OF THE LEGACY OF RAMÓN Y CAJAL TO THE NEUROSCIENCES}

ABSTRACT: Between 1887 and 1897, Santiago Ramón y Cajal carried out a series of micrographic studies that would mark the debate about the structure and the physiology of the nervous system, establishing the theoretical framework for its study in the 20th century. The nature and meaning of the task undertaken by Cajal could not be fully weighed without a serious attempt to establish the pertinent links between such task, its antecedents and its contemporary context. To this end, the first and second sections address the scientific context in which, during the aforementioned period, Cajal elaborated the neuron doctrine and the dynamic polarization law, focusing on the convergent and divergent approaches of previous and contemporary researchers. The third section, on the other hand, is devoted to the discussion of the methodological framework of the formulation of the abovementioned contributions, avoiding recent attempts of historiographical controversy about its paternity and emphasizing that the core of Cajal's legacy does not have to be sought in discussions of this nature, but in the wide body of observations he collected and, particularly, in the profusion of hypotheses he used in order to incardinate those contributions within the theoretical frameworks sanctioned in biological sciences.

KEY WORDS: Ramón y Cajal; neuron doctrine; dynamic polarization law; neuron; neurohistology. 


\section{INTRODUCCIÓN}

En el marco de una continuada e ímproba labor académica e investigadora, Santiago Ramón y Cajal formula entre 1887 y 1897 propuestas teóricas que servirán de base para el posterior desarrollo de la neurohistología, la neurofisiología y, en último término, las neurociencias contemporáneas. La amplia bibliografía acerca del periodo indicado y su impacto en la génesis de las modernas neurociencias ha oscilado con demasiada frecuencia entre la apologética y la detracción, dejando escaso espacio para una consideración ponderada de las aportaciones teóricas, metodológicas y heurísticas de Cajal y el resto de los protagonistas de este episodio fundacional de la historia de las neurociencias. El necesario cotejo de las fuentes originales con las interpretaciones contemporáneas resulta en tal contexto inexcusable.

En 1888 Cajal dio, en sus palabras, con la nueva verdad de la independencia de la neurona. A partir de este momento comienza a describir la microestructura del sistema nervioso al completo, interpretándola como agregado de unidades celulares independientes, unidades anatómicas y fisiológicas del sistema nervioso que Heinrich Wilhelm Gottfried Waldeyer bautizara en aquel mismo momento con el nombre de neurona. ${ }^{1}$ Esta sería su teoría neuronal, de la que ha llegado a decirse que constituye la "base de todos nuestros conocimientos sobre el sistema nervioso" (Reinoso-Suárez, 2002, p. 379). ${ }^{2}$ En 1897, por su parte, formula la versión definitiva de su ley de la polarización dinámica, según la cual las diferentes partes de la célula nerviosa juegan distintos papeles en el curso de la transmisión del impulso nervioso. El marco teórico que ambas aportaciones legaran a los neurocientíficos del siglo subsiguiente ofrecería un campo reelaborado y unificado, dado que gracias al camino recorrido por Cajal en este decenio, la noción de neurona -como atinadamente ha apuntado José Luís González Recio (vid. González Recio, 2007)- queda consistentemente articulada con los marcos teóricos de la citología, la histología, la anatomía descriptiva, la anatomía comparada, la fisiología, la embriología y la teoría de la evolución. ${ }^{3}$ A pesar de que la universalidad de ambas propuestas fuera refutada por trabajos posteriores (vid, v. g., Shepherd, 1972; Fields, 2006), las mismas ofrecieron un feracísimo substrato para la investigación de la estructura y función del sistema nervioso. No obstante, tal y como argumentaremos en el tercer apartado, el trabajo que condujera a la formulación de dichas propuestas no es valorado apropiadamente cuando ellas son presentadas, como es habitual, como el centro de gravedad del legado cajaliano.

\section{HACIA UNA NUEVA CONCEPCIÓN DE LA ESTRUC- TURA Y DINÁMICA DEL SISTEMA NERVIOSO}

Santiago Ramón y Cajal nace en 1852. En ese mismo año aparece la primera edición de la obra clásica de Rudolph Albert von Kölliker Handbuch der Gewebelehre des Menschen, en la cual, dadas las limitaciones de las técnicas histológicas disponibles, la microestructura del sistema nervioso era descrita de forma excesivamente exigua. Kölliker, en las primeras ediciones del señalado libro de texto, expone con franqueza que el problema de elucidar el modo en que las células nerviosas se comunican entre sí permanecía irresuelto -llegando en la cuarta, de $1863,{ }^{4}$ a proponer que el modo en que esta comunicación tiene lugar no podría resolverse mediante microscopía óptica-, pero en la quinta edición, de $1867,{ }^{5}$ esboza la que puede ser tenida por la primera teoría reticularista de la comunicación nerviosa, postulando la existencia de un continuo sin hiatos entre células nerviosas que permitiría la necesaria comunicación entre las mismas. A cubrir la laguna en las descripciones neurohistológicas admitida en las primeras ediciones del libro de Kölliker y a corregir la concepción de la comunicación nerviosa esbozada en la quinta contribuiría decisivamente Cajal, asistido por el desarrollo de la microscopía óptica y las técnicas de tinción basadas en impregnaciones metálicas.

Cajal comienza sus estudios de medicina a finales de la década de los sesenta. En los primeros años de la década subsiguiente se había familiarizado ya con la primera traducción castellana de un texto crucial por lo que a la concepción celular del organismo se refiere: Die Cellularpathologie. En esta obra de 1858 Rudolf Virchow califica de lamentable la laguna en los conocimientos de la época en lo tocante a la histología del sistema nervioso, al carecer, entre otras cosas, de nociones básicas acerca de su estructura citológica. Laín Entralgo propondría más tarde que "la obra de Cajal constituye (...) el definitivo remate de la teoría celular; con lo cual Schleiden, Schwann, Virchow y Cajal vienen a ser los cuatro hitos principales de la historia de esa teoría" (Laín Entralgo, 1978, p. 39). ${ }^{6}$

La obra póstuma de Otto Friedrich Karl Deiters (muerto poco antes de la aparición de la misma con sólo 29 años) Untersuchungen über Gehirn und Rückenmark des Menschen und der Säugethiere fue publicada en los años previos al ingreso de Cajal en la Facultad de Medicina de Zaragoza (concretamente, en 1865). En esta monografía de referencia dentro de la neurohistología europea de la segunda mitad del siglo XIX aparece descrita la constitución básica de la célula nerviosa, que, tal y como Deiters fuera el pri- 
mero en señalar, comprende el cuerpo celular o soma y dos tipos de prolongaciones, a las que llamó el alemán protoplásmicas (dendritas, desde la acuñación de Wilhelm His en 1889) y cilindroejes (axones, desde la acuñación de Kölliker en 1896). ${ }^{7}$ Por otra parte, además de esta descripción básica de la célula nerviosa, desde principios de los cuarenta los trabajos de Kölliker venían ofreciendo, tal y como José María López Piñero supo indicar (López Piñero, 1986, p. 6), una panorámica de la citología nerviosa que parecía dirigirse a la concepción que aún tardaría más de medio siglo en ser generalmente aceptada: la de la independencia de la neurona. Esa concepción neurohistológica acorde con los principios citológicos ya aceptados tardó en cuajar dado que en 1872 Joseph Gerlach defendió, apoyándose en observaciones realizadas con tinciones de cloruro de oro que él mismo ideara, la llamada teoría reticularista o teoría de la red-que en realidad cabe remontar a las observaciones realizadas por Franz von Leydig en 1855 sobre el tejido nervioso de arácnidos (vid., v. g., Clarke y O’Malley, 1996, p. 87)-, según la cual las prolongaciones nerviosas que Deiters describiera forman una red continua a través de la cual tiene lugar la conducción del impulso nervioso, y dado que tanto Kölliker como el resto de las figuras influyentes de la neurohistología europea de aquel momento se adhirieron a las conclusiones de Gerlach, que creía tener en sus preparaciones microscópicas la prueba de la continuidad sin hiatos entre las fibrillas terminales de las dendritas y las células alcanzadas por éstas. Así, Gerlach creía hallar en el sistema nervioso una excepción a la teoría celular elaborada en la década de los treinta por Matthias Jakob Schleiden y Theodor Schwann y por Virchow en la de los cincuenta, pues entendía que el tejido nervioso "was special in the sense that nerve cells are not independet units but instead form a continuous syncytium or reticular net" (Swanson, 2003, p. 20).

La teoría reticular de la estructura y la comunicación nerviosa, que, como señalábamos, puede remontarse a la década de los cincuenta, comienza a elaborarse en la subsiguiente sobre la base de una serie de observaciones citológicas de diversa índole, pero todas relacionadas con la idea de que entre las células nerviosas se producía alguna suerte de fusión. Entre las observaciones que pueden considerarse antecedentes de la formulación de la teoría reticular destacan las de Kölliker, pero también las de Max Schultze. Hacemos aquí mención de las observaciones realizadas por Schultze en 1863 acerca de la fusión de los axones de receptores olfativos que desde el epitelio de la membrana mucosa nasal se dirigen hacia el bulbo ol- fativo por el prestigio del que este investigador gozara en la época. No obstante, sus conclusiones acerca de la fusión de estos finos axones se debieron con certeza a una mala interpretación: la sutileza de aquellos haces de axones podía dar la impresión al microscopio óptico de que éstos acababan por fusionarse, y Schultze pudo desatender que la resolución a la que le era dable trabajar podía no ser suficiente para concluir que aquellos cilindroejes acababan efectivamente fusionándose. Kölliker, por su parte, en la referida quinta edición de su Handbuch der Gewebelehre des Menschen, de 1867, formula a tientas -dado que admite que los medios técnicos disponibles podían no alcanzar a ofrecer la resolución necesaria para apoyar sus planteamientos teóricos- la que más arriba denominábamos "primera teoría reticularista de la comunicación nerviosa” al postular una fusión entre los nervios de las raíces dorsales y ventrales de la médula espinal (Kölliker, 1867, p. 316 y ss.). De estas observaciones de segmentos particulares de la histología nerviosa partiría Gerlach hacia el establecimiento de una teoría reticular general, tarea que llevara a término en 1872. A esta teoría reticular general, es decir, referida a la histología de todo el sistema nervioso, vendría a sumarse poco después el más pertinaz entre los reticularistas, Camilo Golgi. El italiano había elaborado el método de tinción cromoargéntica ${ }^{8}$ que le valdría en 1906 el Nobel compartido con Cajal, ${ }^{9}$ y a partir de 1873 (el mismo año en que Cajal obtiene su Licenciatura en Medicina) comienza a publicar los resultados que obtuvo con dicho método, los cuales conducirían a la publicación, en 1886, de su Sulla fina anatomia degli organi centrali del sistema nervoso. La concepción reticular de Golgi difería, no obstante, de la de Gerlach (vid. Gerlach, 1871; Gerlach, 1872), dado que el italiano proponía que la unidad de la red nerviosa no se basaba en la continuidad de las dendritas, a las que atribuía una función nutritiva -a causa de la relación que encontró entre ellas, el tejido conectivo y vasos sanguíneos-, sino en la unión de las ramas terminales y colaterales de los axones de las diversas clases de neuronas. ${ }^{10}$ Igualmente difería el reticularismo de Golgi del de Hans Held, que defendió un continuismo basado en el contacto de axones con dendritas y axones con somas (Held, 1897), o el de István Apáthy, que sostuvo que las neurofibrillas constituyen el nexo estructural y funcional que, ex hypothesi, mantiene integrada la red nerviosa (Apáthy, 1897). No obstante, el reticularismo de Golgi sería no sólo el que gozara de mayor difusión, sino asimismo el defendido con mayor vehemencia y contumacia por su proponente. 
La teoría de la red no tardaría, sin embargo, en ser desafiada desde diferentes frentes. Así, en el mismo año de la publicación de la referida obra de Golgi aparecieron también publicados los resultados de las investigaciones embriológicas realizadas por Wilhelm His, quien, desde el punto de vista histogenético, defendió la independencia de las células nerviosas al constatar que al menos algunos neuroblastos surgen y migran como células individuales. Al año siguiente, es decir, en 1887, y de forma independiente, August Forel cotejó la obra de Golgi con datos provenientes de la anatomía patológica y la patología experimental, cotejo que le llevaría a conjeturar la independencia de las terminaciones axónicas (en sus trabajos comprobó que al seccionar prolongaciones axónicas la degeneración nerviosa no se extendía, contrariamente a lo que cabría esperar partiendo del marco reticularista, más allá de los somas de las células dañadas). Estos ataques a la teoría reticular no excedieron, sin embargo, las fronteras de las hipótesis basadas en observaciones y trabajos experimentales limitados a momentos puntuales del desarrollo ontogenético y ubicaciones concretas de la anatomía nerviosa, ni tuvieron una significativa repercusión, mientras faltaban aún los fundamentos con arreglo a los cuales elaborar un modelo citológico de la estructura del sistema nervioso en virtud del cual resultara dable establecer una base firme para el desarrollo de la neurofisiología moderna, una nueva fisiología nerviosa basada en la traducción de impulsos eléctricos a mensajes químicos $y$, nuevamente, a impulsos eléctricos que nadie podía aún atisbar y en la elaboración de la cual fue necesario partir de la noción de comunicación por contacto y no por anastomosis. Serían precisamente estas lagunas las que Cajal viniera a llenar con su investigación neurohistológica, en la cual el método de tinción cromoargéntica desarrollado por Golgi jugaría un papel fundamental. Otros, como su antiguo compañero en la Universidad Central de Madrid Luis Simarro -que, precisamente, durante una visita de Cajal a su laboratorio en 1887 había transmitido a éste la técnica desarrollada por Golgi (vid. López Piñero, 2006, p. 211 y ss.; Durán Muñoz y Alonso Burón, 1983, p. 173 y ss.)-, habían abandonado la esperanza de alcanzar resultados utilizando dicho método. Cajal, sin embargo, "después de su encuentro con Simarro (...) comenzó inmediatamente a usar el método de Golgi para estudiar prácticamente todo el sistema nervioso" (De Felipe, 2007a, p. 55). Perseveró, pues, en la utilización del mismo y lo perfeccionó desarrollando una útil variación ${ }^{11}$ y determinando las condiciones apropiadas para su mejor aplicación a diversas clases de tejido.
Así, en buena medida gracias a este método, describiría Cajal entre 1887 y 1903 la microorganización del sistema nervioso prácticamente al completo, en una serie de estudios de los que partiría para la elaboración de su obra principal, Textura del sistema nervioso del hombre y de los vertebrados, obra que jalona la historia de las neurociencias.

Una de las claves que el método de tinción de Golgi ofreciera al desarrollo de la teoría neuronal de Cajal se halla en el hecho de que con él la tinción es selectiva, esto es, afecta a la célula que alcanza viéndose frenada la impregnación del tejido por la membrana plasmática y no extendiéndose así a la siguiente célula. Esta particularidad del método de Golgi ofreció sustento a la teoría neuronal de Cajal, aunque no todos los investigadores implicados en la controversia interpretaron dicha particularidad como un argumento a favor de la independencia de la célula nerviosa, dado que cabía entender, por ejemplo, que determinado tipo de sustancia desconocida pero garante de la continuidad entre células no se viera afectada por el método de tinción de Golgi. No es de extrañar que surgieran estas discrepancias, dado que cuando dos células sucesivas resultan impregnadas con el método de Golgi dan la sensación, al microscopio óptico, de encontrarse unidas y, además, incluso a día de hoy los fundamentos bioquímicos del método de Golgi son desconocidos y no han sido todavía esclarecidos los motivos por los cuales unas células resultan con él impregnadas mientras otras no lo hacen. Así, el método de Golgi, cabe decir, permitía inferir, exclusivamente, la discontinuidad de un misterioso proceso de impregnación, pero de ningún modo pudo hacer visible al microscopio óptico el hiato que efectivamente separa los elementos pre y postsinápticos, pues el mismo se halla más allá de la resolución que puede ofrecer la microscopía óptica. Abundando en las técnicas utilizadas por Cajal en este momento crucial de su carrera científica, otra exitosa apuesta metodológica fue en este punto la sustitución de la selva adulta por el joven vivero. ${ }^{12}$ Cajal se expresa en estos términos en sus Recuerdos de mi vida (Ramón y Cajal, 1917/1923/2006, p. 403) aludiendo a la importancia que en esta etapa de su trayectoria tuviera la decisión de estudiar el tejido nervioso de embriones y animales jóvenes en lugar de adultos, decisión tomada con vistas a la mejor observación de las diferentes partes de la célula, que en fases tempranas del desarrollo no se halla aún sumergida en la inextricable maraña de ramificaciones dendríticas que caracterizan lo que Cajal denominara selva adulta. ${ }^{13}$ Por otra parte, optar por el estudio micrográfico de sistemas nerviosos de 
pequeños mamíferos, aves, embriones y ejemplares jóvenes trajo aparejada la ventaja de una mejor impregnación de los tejidos debida a la menor densidad de mielina presente en las preparaciones.

En este momento, es decir, a finales de la década de los ochenta, además de publicar artículos en diversas revistas médicas, costea Cajal la edición de su propia revista, la Revista trimestral de Histología normal y patológica, en la que publica sus resultados incluyendo láminas litográficas que él mismo dibujara y grabara. A pesar de que sólo aparecieron tres números de esta revista, ${ }^{14}$ hemos de entender su publicación como un punto de inflexión en la historia del estudio del sistema nervioso, pues en esta corta andanza editorial Cajal publica una decena de artículos que pueden ser leídos hoy como poco menos que documentos fundacionales de las neurociencias contemporáneas. La atención prestada por Cajal al cerebelo fue de gran importancia en esta época, dado que el patrón de conectividad entre las células de esta región encefálica, mucho más claro y sencillo que en el córtex, facilitó ostensiblemente su labor descriptiva. No se trataría de una atención aislada, pues de 222 artículos sobre el sistema nervioso, Cajal publicó un total de 49 dedicados íntegra o principalmente a diferentes aspectos de la anatomía, citoarquitectura y fisiología de esta región encefálica (vid. Toledano, 1983). Serían, justamente, una serie de estudios micrográficos realizados con cerebelos de aves (Ramón y Cajal, 1888a), una serie de estudios cuyos resultados aparecieron publicados en un artículo recogido en las primeras páginas del primer número de la Revista trimestral de Histología normal y patológica, ${ }^{15}$ los que ofrecieran a Cajal la oportunidad de convencerse de que "cada elemento [nervioso] es un cantón fisiológico absolutamente autónomo" (Ramón y Cajal, 1888a, p. 9), un convencimiento que expresara inicialmente con cautela. Un convencimiento aparejado a éste sería ya en aquel momento el de que el impulso nervioso no pasa de célula a célula sin salvar antes alguna suerte de hiato -que desde la acuñación de Charles Scott Sherrington (Sherrington, 1897, p. 929) denominamos sinapsis-, es decir, que no tiene el mismo lugar continuamente, sino por contacto. ${ }^{16}$ Sus observaciones anatómicas le condujeron así a la hipótesis fisiológica "de la trasmisión por contigüidad de las acciones nerviosas" (Ramón y Cajal, 1888b, p. 39). Es de este modo enteramente manifiesto el vínculo entre anatomía y función ${ }^{17}$ que guiara el trabajo observacional, experimental, descriptivo y teórico que Cajal emprende a finales de la década de los ochenta para la demostración de la individualidad de la célula nerviosa, que ensayara sucesivamente en el cerebelo, la retina y la médula espinal y que culmina en la década subsiguiente con la formulación de la ley de polarización dinámica. ${ }^{18}$

Las propuestas de Ramón y Cajal no fueron inmediatamente acogidas sino con escepticismo por la comunidad histológica internacional, ${ }^{19}$ y esto a pesar de que entre finales de 1889 y principios de $1890^{20}$ enviara el histólogo español traducciones francesas de los artículos en los que exponía los principales resultados de sus investigaciones a las más prestigiosas revistas europeas de anatomía. Así, a los primeros textos en los que Cajal presenta resultados conducentes a su teoría neuronal respondieron de forma crítica, junto con Golgi, Franz Nissl, István Apáthy, Hans Held y, poco después, Hans Albrecht Bethe, a cuyos estudios anatomo-patológicos en defensa de la hipótesis reticularista (Bethe, 1901) respondiera a su vez Cajal con estudios análogos (Ramón y Cajal, 1905; Ramón y Cajal, 1906) de los que se sirvió para confutar las conclusiones de Bethe. No es de extrañar que la actitud predominante entre las grandes figuras de la neurohistología de la época hacia los descubrimientos del aragonés presentara el señalado cariz del escepticismo y la desconfianza, dado que la concepción de la estructura del sistema nervioso que de los mismos se desprendía chocaba con supuestos neurohistológicos y neurofisiológicos vigentes y celosamente defendidos por la mayoría de las figuras destacadas en el área. En vista de ello, Cajal, consciente de que la difusión de sus descubrimientos se topaba con dificultades que el envío de artículos a revistas y comunicaciones a las principales figuras de la comunidad histológica internacional no alcanzaba a salvar, se decide a costearse un viaje a Berlín para presentar las preparaciones micrográficas que más claramente apoyaban su nueva concepción de la microanatomía nerviosa en el congreso de la Sociedad Anatómica Alemana celebrado en octubre de 1889. La presencia en dicho congreso de Kölliker jugaría a la postre un nada desdeñable papel en la aceptación y difusión de las propuestas de Cajal. El reputado histólogo y zoólogo suizo venció su inicial desconfianza a la luz de las claras preparaciones de Cajal y, posteriormente, realizó una serie de trabajos de confirmación ${ }^{21}$ utilizando el método de la doble impregnación (vid. nota 11) que servirían no sólo para que él mismo abandonara la teoría reticular, sino también para preparar el terreno para la difusión y consolidación de la nueva concepción de la estructura del sistema nervioso. El abandono por parte de Kölliker de la teoría reticular sería pronto imitado por el resto de las figuras destacadas de la neurohistología europea, desde Waldeyer hasta Mihály Lenhossék, ${ }^{22}$ 
Gustav Retzius,, ${ }^{23}$ Arthur van Gehuchten o Mathias Duval, y no sólo eso, sino que pronto Kölliker, Lenhossék, Retzius y van Gehuchten replicarían y confirmarían las observaciones de Cajal. No obstante, Golgi seguiría defendiendo vehementemente la teoría reticular durante el resto de su vida, ${ }^{24}$ aunque ya en solitario. ${ }^{25}$

Transcurridos apenas dos años desde el congreso de la Sociedad Anatómica Alemana Cajal formula su ley de la polarización dinámica, que expuso por vez primera en julio de 1891 en una comunicación pronunciada en el Primer Congreso Médico-Farmacéutico Regional, celebrado en Valencia. Dicha comunicación aparecería publicada en las actas del congreso bajo el título "Comunicación acerca de la significación fisiológica de las prolongaciones protoplásmicas y nerviosas de las células de la sustancia gris", siendo su contenido desarrollado en el artículo de 1897 "Leyes de la morfología y dinamismo de las células nerviosas". El núcleo de la referida comunicación se erige como uno de los mayores logros de la carrera científica de Cajal, dado que en él se define por primera vez el curso de la transmisión del impulso nervioso, en el que el axón se comporta como órgano emisor y el soma y las dendritas como aparatos receptores: "la transmisión del movimiento nervioso tiene lugar desde las ramas protoplásmicas hasta el cuerpo celular, y desde éste a la expansión nerviosa" (Ramón y Cajal, 1891, p. 70). ${ }^{26}$ Establece de este modo Cajal un principio fisiológico estrechamente vinculado con sus postulados microanatómicos cuya trascendencia resulta difícil exagerar, pues será sobre él que se eleve el edificio de las neurociencias contemporáneas, por cuanto con el señalado principio consigna Cajal a las venideras generaciones de investigadores una definida orientación acerca de la dirección y el lugar en que investigar los procesos neurofisiológicos cruciales, esto es, los relacionados con la dinámica de la comunicación entre las células nerviosas, en los cuales radican, en último término, las principales funciones desempeñadas por el sistema nervioso en la economía del organismo. Con la ley de la polarización dinámica, otrosí, y en términos lakatosianos (Lakatos, 1978), un postulado se desplaza del cinturón protector al núcleo teórico: el postulado de economía de materia, tiempo y espacio en la comunicación nerviosa (vid. Ramón y Cajal, 1897), una economía relacionada en este caso con la monopolaridad del impulso nervioso, que acorta las vías y, así, el tiempo que el impulso nervioso ha de emplear en recorrerlas. ${ }^{27}$ Cajal, poniendo de manifiesto su atención a la biología evolucionista, entendía este principio de economía como vinculado con la filogenia, e hizo uso del mismo, por ejemplo, en la elaboración de su ingeniosa explicación evolutiva del origen de la decusación de los tractos motores como adaptación destinada a aumentar la eficacia de la coordinación visomotriz (Ramón y Cajal, 1899, pp. 654-656).

\section{ALGUNAS CUESTIONES DE HISTORIA Y METODO- LOGÍA DE LA CIENCIA}

Hemos visto cómo entre los dos últimos años de la penúltima década del siglo XIX y los siete primeros de la última Cajal sienta las bases para una nueva concepción de la microanatomía y la fisiología de sistema nervioso. El primer paso sería el establecimiento de la teoría neuronal, con la cual diluye la particularidad del tejido nervioso tal y como venía siendo concebido. Alcanzados estos resultados, es decir, delimitada la identidad citológica de la neurona, afronta la tarea de esclarecer los principios dinámicos de la actividad nerviosa, tarea que desemboca en la formulación de la ley de la polarización dinámica, que explicita y define un concretísimo vínculo entre morfología y fisiología.

Sentados en el lapso de apenas cuatro años aquel principio eminentemente morfológico de finales de los ochenta y este principio funcional enunciado a comienzos de la década de los noventa, Cajal ofrece a la neurociencia posterior un campo reformado y un fructífero substrato del que no tardarían en brotar los más insospechados frutos. La década de los treinta, en la que pereciera Cajal, asistió al inicio de la investigación de los mecanismos de la transmisión nerviosa. Adheridos a los planteamientos de Cajal, los neurofisiólogos de la época comienzan a desentrañar el funcionamiento del potencial de acción -una investigación cuya historia se prolonga de Luigi Galvani a las ecuaciones Hodgkin-Huxley- y a identificar neurotransmisores, una investigación que de Emil du BoisReymond (vid. Finger, 1994, p. 48) Ilega a nuestros días. Algunos de los grandes hitos del desarrollo de las neurociencias habrían de esperar, no obstante, a la década de los cuarenta, a partir de la cual se producirían destacados logros de la mano de Donald Hebb, David Hubel, Torsten Wiesel, Vernon Mountcastle, Roger Sperry o Wilder Penfield. ${ }^{28}$

Con todo, la insinuada distinción dentro de este breve periodo de la carrera de Cajal entre una primera etapa atenta a la morfología y una segunda dedicada al estudio de la neurofisiología no deja de resultar artificial dado el carácter de la labor cajaliana, el cual pone de manifiesto desde un primer momento que su búsqueda de una cabal comprensión del sistema nervioso atiende a la estructura sin separarla de la función. "[Cajal] no sólo quería describir, 
como lo hace la histología normal, la estructura del sistema nervioso, sino entender su función a partir de esa estructura" (Estañol, 2007, p. 78). Así, su hipótesis morfológica sobre la independencia de la neurona se vería orientada por su preocupación por la función que cabría entender que desempeñan las prolongaciones protoplasmáticas, al tiempo que su ley de la polarización dinámica surge auspiciada por observaciones microanatómicas.

Un brevísimo apunte acerca del Cajal metodólogo ${ }^{29}$ resulta pertinente en este punto, esto es, una vez presentado el contexto del nacimiento de la teoría neuronal y la ley de polarización dinámica y antes de pasar a comentar algunas cuestiones polémicas relacionadas con el señalado nacimiento. Por lo que toca al Cajal metodólogo, pues, cabe señalar que, a pesar de que el modo en que presenta algunos de sus hallazgos como mero fruto inductivo de la observación y la experimentación puede llevar a pensar en él como un empirista ingenuo, ${ }^{30}$ Cajal no dejó de ser consciente del papel orientador que el nivel teórico juega en la observación. "Su atención (...) a los problemas conceptuales y a los lazos que la neurohistología había de establecer con la citología, la microanatomía, la embriología, la fisiología general o la teoría de la evolución parecen indicar que era consciente de que el rumbo de la ciencia no se dirime sólo en la esfera de la observación, los fenómenos establecidos y la inducción" (González Recio, 2007, p. 31). Cajal, "extraordinario observador e intérprete de las imágenes microscópicas" (De Felipe, 2007b, p. 82), entendía que la observación desnuda, sin la guía de las hipótesis, a pocas metas científicas podría conducir. Pero no deja de ser igualmente cierto que tampoco cabe afirmar que su concepción de la metodología científica incluyera una noción explícita del modo en que el plano teórico interviene en la experiencia y la interpretación de la misma, con lo cual pudo seguir confiando en la posibilidad de apelar a una experiencia pura como base para la confirmación de hipótesis y teorías científicas y, por tanto, convencido de que la teoría neuronal no era sino un "puro resultado inductivo del análisis estructural" (Ramón y Cajal, 1917/1923/2006, p. 401). Con todo, a la base de la apuntada "inducción pura" no se hallaba una observación acendrada de intuiciones rectoras y concomitancias teóricas acerca de lo observado: Cajal jamás pudo observar la efectivamente existente discontinuidad entre elementos nerviosos que desde Sherrington denominamos sinapsis, extremo de no escasa relevancia habida cuenta de la centralidad de la cuestión de la separación física entre los elementos pre y postsinápticos para la teoría neuronal.
Estrechamente vinculadas con estas dificultades metodológicas se hallan una serie de consideraciones de índole historiográfica que plantearemos tomando como punto de partida una polémica que cumple ya un cuarto de siglo sin haberse mostrado excesivamente fértil. Partiremos pues de la misma, mas sin la intención de entrar en ella sino para realizar las matizaciones pertinentes de cara a propiciar una justa consideración del contexto del que surgiera la teoría neuronal.

Aludíamos en el segundo apartado a los ataques que desde dos años antes de que Cajal ofreciera acabada su nueva verdad de la independencia de la neurona había recibido el reticularismo de la mano de las investigaciones embriológicas realizadas por Wilhelm His y las anatomopatológicas de August Forel. Estos ataques a la teoría reticular, como señalábamos, no excedieron las fronteras de las hipótesis escasamente articuladas y limitadas a ámbitos concretos de la citología nerviosa, ni tuvieron, a pesar de la innegable penetración de las observaciones y la manifiesta convicción acerca del significado de las mismas expresada por sus postulantes, una significativa repercusión en sus contemporáneos. Mientras tanto, como asimismo señalábamos, faltaban aún los fundamentos con arreglo a los cuales elaborar un modelo celular de la estructura del tejido nervioso en virtud del cual resultara dable establecer una base firme para la nueva neurofisiología. Y no sólo esto, faltaba elaborar cabalmente semejante marco teórico y comenzar a compilar un cuerpo sistemático de evidencias que lo sustentaran y sirvieran para que la comunidad científica del momento abrazara la nueva verdad. Esta fue la empresa que Cajal emprendiera y llevara a término. Aun así, los señalados ataques tempranos al reticularismo han servido a Marcus Jacobson para aseverar que el descubrimiento de la independencia de la neurona debe atribuirse a His y Forel, no a Cajal, del cual ofrece, abusando de un singular ánimo polémico y un exceso de especulación psicosocial, un retrato obstinado, inmodesto y narcisista (Jacobson, 1993). La discusión en torno al "verdadero padre de la neurona" se nos antoja, en todo caso, poco interesante mientras siga abierta la más atractiva posibilidad de atender al contenido de los trabajos de unos y otro y otorgar el debido valor a las investigaciones y conclusiones de cada uno. No consideramos, pues, necesario dar pábulo a semejante clase de polémica, y menos cuando la misma, transcurrido ya un cuarto de siglo, ha resultado escasamente fecunda: sólo un par de reseñas, publicadas, eso sí, en revistas de prestigio (Nature y Trends in Neuroscience), han sido consagradas a la 
discusión, principalmente, del estilo y de algunos de los fragmentos más estridentes del libro de Jacobson. Las alusiones que siguen no han de ser entendidas pues como conato de respuesta a la pregunta acerca del verdadero padre de la teoría neuronal, sino antes bien como un intento de ofrecer en pocas frases una perspectiva mesurada acerca de algunos puntos que no deberían dejar de ser tenidos en cuenta de cara a entrar en semejante debate. Sentado esto, sobra aducir que de ningún modo cabe obviar afirmaciones tan contundentes acerca de la independencia de las células nerviosas como las contenidas en "Einige hirnanatomische Betrachtungen und Ergebnisse", artículo publicado en el año anterior a la aparición de "Estructura de los centros nerviosos de las aves" -y el resto de la decena de artículos a los que hacíamos referencia en el apartado anterior- en el que Forel afirma estar cada vez más convencido de que las supuestas redes continuas descritas por los reticularistas no son sino entramados de axones con terminaciones libres (Forel, 1887, p. 166). Con todo y con ello, obviar que fue, efectivamente, Cajal el más laborioso y tenaz defensor de la incipiente teoría neuronal, que él la elaboró y apoyó teórica y empíricamente con una resolución y amplitud sin precedentes (analizando la citoarquitectura del sistema nervioso al completo), y, asimismo, que fue él quien ofreció a la comunidad científica "el aplastante cuerpo de evidencia microscópica que la teoría neuronal requería" (Jones, 1994, p. 544) y fue así "el científico que más datos aportó para su demostración" (De Felipe, 2007b, p. 40), constituye, cuando menos, un grave descuido historiográfico. Cajal, por su parte, nunca sintió la necesidad de ocultar la prioridad de His y Forel en la labor de comenzar a minar la teoría reticular con sus publicaciones de 1886 y 1887 , época en la que él comenzara a utilizar el método de tinción cromoargéntica -hay que añadir que totalmente ignaro de los resultados obtenidos por sus colegas suizos.

\section{CONCLUSIÓN}

No cabe relegar la originalidad de la aportación de Cajal a las neurociencias a la discusión acerca de la paternidad de la teoría neuronal, sino, tras una atenta consideración del hecho de que "Cajal no hizo un solo gran descubrimiento, sino que realizó numerosas e importantes contribuciones al conocimiento de la estructura y función del sistema nervioso" (De Felipe, 2007b, p. 19), situarla en su audacia y prolijidad a la hora de plantear hipótesis y su meticulosidad al idear métodos para tratar de contrastarlas. Sin embargo, por lo que toca a la teoría neuronal, dichos métodos nunca pudieron superar un obstáculo: Cajal, cuyos escritos de aliento metodológico apuntan a una concepción de la observación y la experimentación como tribunales definitivos e independientes para la confirmación de hipótesis científicas, jamás pudo ver una sinapsis. Sencillamente, resultan invisibles mediante microscopía óptica. De este modo, evidencia empírica de tipo indirecto y, especialmente, una intuición teórica basada en principios citológicos bien establecidos contarían como los elementos constituyentes de la convicción de Cajal y el resto de la comunidad científica que desde la década de los noventa comenzó a adherirse a la nueva verdad. Hay que acotar pues las citas antepenúltima y penúltima (de Jones y De Felipe, respectivamente) señalando que no sería hasta fecha posterior a la invención del microscopio electrónico por parte de Max Knoll y Ernst Ruska (en 1932) que pudiera observarse una sinapsis, y que no sería hasta 1955 que aparecieran publicadas las primeras microfotografías electrónicas de una sinapsis en las que pudiera observarse la discontinuidad estructural entre los elementos pre y postsinápticos, aportándose así definitivamente evidencia inequívoca en sustento de la teoría neuronal (vid. Cowan; Kandel, 2001, p. 47), una evidencia innecesaria, dado que para entonces los planteamientos reticularistas no eran considerados como una posibilidad seria por ningún investigador. Así, la temprana afirmación de Cajal según la cual "las células nerviosas son elementos independientes jamás anastomosados" (Ramón y Cajal, 1889c, 480) no pudo basarse en una observación directa, de forma que cuando, en el mismo artículo, ataca el postulado reticularista asegurando no haber "podido ver una malla de semejante red, ni en el cerebro, ni en la médula, ni en cerebelo" (Ramón y Cajal, 1889c, 480), basándose en la sola observación de sus preparaciones microscópicas podría con igual justeza haber apuntado que tampoco tuvo ocasión de contemplar en las mismas la discontinuidad efectivamente existente entre elementos nerviosos. El origen de la teoría neuronal se halla así, antes que en un conjunto de observaciones rectoras, en la orientación que las mismas obtuvieron de principios citológicos básicos y de la intuición de la necesidad o, cuando menos, la conveniencia de emprender la búsqueda de principios fisiológicos y neurohistológicos coherentes con los ya sentados en citología y que no postularan, de este modo, un hiato entre la naturaleza del tejido nervioso y la del resto de los tejidos para el cual, en cualquier caso, habría que encontrar a posteriori una justificación de la que nadie disponía. Hay pues que comprender, por lo que al surgimiento de la teoría neuronal 
respecta, el cuerpo de datos organizados que de su labor experimental y sus observaciones obtuvo y difundió Cajal como un excelente complemento del verdadero centro de gravedad de sus aportaciones: su búsqueda de principios integradores de la función y organización nerviosa y su formulación, de acuerdo con los mismos, de propuestas explicativas de gran alcance acerca de casi cada aspecto de la morfología y la fisiología neuronal de algún modo abordable mediante la tecnología de la época -como las mencionadas acerca del aprendizaje o el significado evolutivo de la decusación de los tractos motores, y asimismo como su famosa hipótesis neurogenética según la cual

\section{NOTAS}

1. Waldeyer procuró mantener una postura prudente cuando en sus artículos de la década de los noventa conceptualizó la neurona como unidad celular, mas no como unidad funcional (vid., v. g., Jacobson, 1993, p. 163). En la obra citada en esta nota al pie, de hecho, en la página señalada, puede leerse una traducción no demasiado fiel del famoso comentario de Cajal en sus Recuerdos de mi vida acerca del acuñamiento de Waldeyer: "Waldeyer, a quien la Histología debe en otros dominios cardinales revelaciones, no investigó personalmente el problema de las conexiones interneuronales, limitándose a hacer en un semanario alemán un resumen popular de mis trabajos, y a inventar la palabra neurona" (Ramón y Cajal, 1917/1923/2006, pp. 716-717; cursivas en el original). Volveremos sobre el polémico texto de Jacobson en la tercera parte de este trabajo.

2. La teoría neuronal de Cajal es a menudo presentada como la mayor revolución de todos los tiempos en el campo de las neurociencias (vid., v. g., García Segura, 2005, p. 16). En la misma línea, la inmensa mayoría de los recientes repasos históricos al origen y desarrollo de la teoría neuronal esbozan un relato en el que la misma aparece como un hito fundamental en el surgimiento y consolidación de los métodos y marcos teóricos cardinales de las neurociencias contemporáneas (vid., v. g., Van der Loos, 1967; Shepherd, 1991; Jacobson, 1993; Clarke y O’Malley, 1996; Albright, et. al., 2000; Bennett, 2002; Cowan y Kandel, 2002; Glickstein, 2006). No obstante, otros matizan que la teoría neuronal, a pesar de su importancia heurística como guía teórica para la investigación durante la primera mitad del siglo XX, ha hecho ya su trabajo y no forma parte del acerbo científico necesario para la formación e investigación en neurociencias, hablando así de una neurociencia posneuronista (Guillery, 2005).

3. Las aportaciones de Cajal a la neuroembriología y la neurogenética durante el periodo considerado son de una relevancia asimilable a la de su estudio histológico del sistema nervioso, a cuyas implicaciones microanatómicas y neurofisiológicas dedicamos el presente artículo (vid. la migración neuronal y el crecimiento axonal se hallan regulados por quimiotaxis (Ramón y Cajal, 1892), hipótesis sólo alejada de las actuales neurotrofinas y moléculas de adhesión celular por la distancia técnica y conceptual que el transcurso de más de un siglo impone a la praxis y el léxico científico.

Ramón y Cajal, sin disponer de la tecnología necesaria al efecto, supo ver, sin poder ver efectivamente, gran parte de la neurofisiología y la microestructura del sistema nervioso que las generaciones subsiguientes irían descubriendo paulatinamente, guiadas en gran medida por las feraces descripciones, hipótesis e intuiciones del incansable científico aragonés.

Baratas Díaz, 1997; Puelles López, 2009). No puede dejar de mencionarse en relación a dichas aportaciones su hipótesis neurotrópica (vid. Ramón y Cajal, 1892), que vino a ofrecer una innovadora explicación quimiotáxica de la migración neuronal y el crecimiento axonal, anticipándose más de medio siglo al descubrimiento de neurotrofinas y moléculas de adhesión celular y legando una concepción plástica y dinámica de la ontogenia nerviosa fecunda al punto que cabe presentarla como esencialmente vigente.

4. Resulta interesante señalar en este punto que en los meses previos a esta cuarta edición aparece descrita y demostrada por vez primera la libre terminación de axones motores sobre sus músculos diana (vid. Krause, 1863; Kühne, 1862). La demostración de Kühne se basó en experimentación anatomopatológica, al comprobar que la desaparición del músculo inervado no devenía en la degeneración de los nervios que a él llagaban. Esta demostración sería posteriormente utilizada por Waldeyer y Wilhelm His entre 1889 y 1891 como argumento a favor de la libre terminación de todo axón.

5. La comparación de esta quinta edición con la sexta y definitiva, de 1896, arroja ya a primera vista un curioso saldo, claramente indicativo de la transformación en curso en la disciplina: mientras el uso de la palabra "red» (Netzwerk), abundante en la primera, se reduce hasta casi desaparecer en la segunda, las referencias a la obra de Cajal, lógicamente inexistentes en la primera, superan la centena en la segunda.

6. La relación entre la teoría neuronal de Cajal y la teoría celular gestada medio siglo antes ha sido subrayada por gran cantidad de comentaristas. La forma más sencilla de concebir dicha relación, implícita en nuestra cita de Laín Entralgo, puede hallarse planteada en los términos más explícitos por Brodal (Brodal, 1948/1969), que presenta la teoría neuronal como una simple extensión de la teoría celular. Otra forma en la que habitualmente es presentada una idea similar incide en el modo en 
que la teoría reticular suponía un desafío para la teoría celular. Eric R. Kandel, uno de los neurocientíficos de mayor fama internacional, cuenta entre quienes se han sumado a esta forma de presentar la señalada relación entre la teoría celular y la teoría neuronal (vid., v. g., Albright et. al., 2000; Cowan y Kandel, 2001). Por nuestra parte, y sin la intención de abundar en el particular, nos adherimos respecto de esta segunda forma de presentar la relación entre teoría neuronal y teoría celular al juicio de Guillery, que cita esclarecedores ejemplos históricos de reticularistas que no encontraban contradicción entre la teoría celular y la posibilidad de una neurohistología continuista, a los que suma ejemplos de otras áreas de la anatomía en las que tampoco hallaron los histólogos contradicción entre la teoría celular y la posibilidad de tejidos sin hiatos. "Given the occurrence of cell fusions in non-neural tissues, fused neural processes cannot be seen as a challenge to the cell theory, only to the neuron doctrine" (Guillery, 2005, p. 1284).

7. Véase la Tabla 1 en el apéndice del referido texto de Deiters, así como el texto que describe la Figura 1 de dicha tabla (Deiters, 1865, p. 316) y el que a ella remite (Deiters, 1865, p. 56).

8. Según la leyenda, el método habría surgido fortuitamente al observar Golgi unas muestras de tejido nervioso que habían sido fijadas en dicromato potásico y arrojadas posteriormente en un recipiente que contenía nitrato de plata por una señora de la limpieza (vid. Alonso, 1994, p. 24). En cualquier caso, el método consistía en el endurecimiento de bloques de tejido nervioso mediante tratamiento prolongado con dicromato potásico y ácido ósmico seguido de una inmersión, para su tinción, en una solución de nitrato de plata. Al seccionar posteriormente el bloque, podía apreciarse al microscopio cómo la tinción, fruto de la precipitación del cromato argéntico, dotaba de un tono negro sólo a algunas células, haciendo visibles sus árboles dendríticos y sus axones.

9. Es conocido el hecho de que Golgi no supo desprenderse de su reticularismo y, en fecha tan tardía como 1906, encontró arrestos para aprovechar una ocasión tan poco propicia como la ceremonia de entrega del Nobel compartido para arremeter contra la teoría neuronal. "I cannot abandon the idea of a unitary action of the nervous system, without bothering if, by that, I approach old conceptions" (Golgi, 1906, p. 216). Comentando la desconcertante intervención del italiano en la ceremonia, Stanley Finger, en un intento por cartografiar las impresiones de la audiencia, formula la pregunta: "How could this man, of all men, be so blind to new findings?" (Finger, 2000, p. 215). Esta alocución, ciertamente, enturbió la ceremonia de entrega del primer Nobel compartido en la categoría de Fisiología o Medicina, más aún teniendo en cuenta que serían métodos muy similares los que condujeran a ambos galardonados a planteamientos teóricos totalmente opuestos.

10. La distancia entre sus planteamientos y los que pronto defendería Cajal se hace totalmente explícita ya en los primeros textos en los que éste presenta su teoría neuronal: "todo cilinder axis, cualquiera que sea su disposición y longitud conserva su individualidad en toda su extensión sin anastomosarse jamás con otros cilinders ni constituir redes de terminación" (Ramón y Cajal, 1889a, p. 66).

11. Consistente en aplicar a las preparaciones histológicas un adicional baño bicrómico y una nueva impregnación argéntica después de extraerlas de la inicial solución de nitrato de plata.

12. Explica en esta época Cajal los motivos que le llevaran a optar por trabajar con sistemas nerviosos inmaduros: "Esperábamos hallar, trabajando en órganos nerviosos jóvenes, una trama estructural que sin diferir sustancialmente de la de los adultos, nos mostrara los rasgos fundamentales de la de éstos, y permitiera abordar con más fruto el estudio de la médula y cerebro humanos" (Ramón y Cajal, 1889b, p. 79).

13. Algunos (vid., v. g., Albarracín Teulón, 1997), a la luz del énfasis en la micro-anatomía comparada que recorre la obra de Cajal, han encontrado en esta apuesta metodológica la influencia de la teoría darwiniana de la evolución.

14. En realidad cuatro, apareciendo los números 3 y 4 conjuntamente en el último lanzamiento, de marzo de 1889.

15. Resulta interesante el hecho de que precisamente este artículo comience con la frase: "Las investigaciones de Golgi sobre la textura de los centros nerviosos han abierto una nueva era" (Ramón y Cajal, 1888a, p. 1), pues precisamente Golgi contaría entre los pocos que jamás aprobarían el fundamento de esa nueva era: la teoría neuronal de Cajal.

16. Así afirmaría al año siguiente que "la propagación de la acción nerviosa se verifica por contactos a nivel de ciertos aparatos o disposiciones de engranajes" (Ramón y Cajal, 1889c, p. 480).

17. "Everyone who has had the pleasure of reading Ramón y Cajal's works knows that his splendid neauroanatomical studies were always presented in a functional context" (Llinás, 2003, p. 77).

18. Este vínculo entre anatomía y función se haría totalmente explícito en la Croonian Lecture que Cajal impartiera, invitado por Michael Foster y Charles Sherrington, ante los miembros de la Royal Society (Ramón y Cajal, 1894), en la que ofrece una panorámica eminentemente fisiológica de su investigación de la anatomía microscópica del sistema nervioso.

19. Tal y como Arthur van Gehuchten lo expresara en un elocuente texto de 1913, "los hechos descritos [por Cajal] en sus primeras publicaciones resultaban tan extraños que los histólogos de la época (...) los acogieron con el mayor escepticismo" (citado en De Felipe, 2007b, p. 36). 
20. Sólo a lo largo de este año publicaría Cajal nada menos que diecinueve artículos, una tercera parte de los cuales aparecerían en francés en diferentes revistas europeas.

21. Trabajos que verían la luz poco después en la revista que el propio Kölliker editaba (Zeitschrift für Wissenschaftliche Zoologie). El interés de Kölliker por la obra de Cajal le condujo al estudio de nuestro complicado idioma cuando contaba más de setenta años. De este modo pudo traducir y publicar en su revista un artículo de Cajal sobre el hipocampo.

22. En una carta a Cajal de enero de 1890 se expresa el histólogo húngaro en estos términos: "tengo ahora mucho que lamentar el no haber comprendido antes toda la importancia de los trabajos de usted, y haber mostrado acerca de ellos un escepticismo injustificado, que espero habrá usted sabido olvidar" (citado en Lopera Chaves, 2008, p. 31).

23. Por suerte, de entre la enorme proporción del legado epistolar de Cajal perdido o no recuperado -en muy buena medida a causa de la sorprendente negligencia de sus gestores- podemos excluir su correspondencia con el sueco, recogida en el tercer capítulo del loable y esmerado esfuerzo editorial de Fernández Santarén (2014).

24. Con todo, Cajal no tardaría en granjearse adeptos entre los hombres de ciencia italianos. Así, por ejemplo, el psiquiatra Eugenio Tanzi (vid. Tanzi, 1898) fue uno de los primeros en adherirse a las conclusiones de Cajal acerca de la individualidad de las células nerviosas, acompañando asimismo a Cajal en sus hipótesis acerca de la función de las dendritas y en la neurofisiología del aprendizaje que de Donald Hebb a Eric Kandel ha venido desarrollándose con posterioridad en la dirección trazada inicialmente por Cajal (vid. Chóliz Montañés, 1992; Berlucchi y Buchtel, 2009).

25. La pugna inicial entre los planteamientos reticularistas y neuronistas conduciría a la publicación, a petición del editor Levandoswky, de una extensa revisión en la que Cajal expone los principales hallazgos que le condujeran a su concepción de la independencia de la neurona. El texto, definido por destacados especialistas como el testamento científico de Cajal (vid. Reinoso Suárez, 1988), apareció inicialmente publicado en español en 1933 bajo el título “¿Neuronismo o reticularismo?” (Ramón y Cajal, 1933), y al año siguiente, poco después de la muerte de Cajal, en una versión ampliada en Francés. Un año más tarde aparecería en el Handbuch der Neurologie el que puede considerarse el documento postrero y definitivo de la teoría neuronal de Cajal, un texto en el que el aragonés presenta las seis características que, en su planteamiento, confieren a la neurona su individualidad -unidad morfológica, genética, funcional, regenerativa, de reacción patológica y de conducción- y expone su principio de la polarización dinámica (Ramón y Cajal, 1935).

26. Es interesante señalar que, en el marco de la polémica mantenida con Van Gehuchten (vid. Van Gehuchten,
1891; Van Gehuchten y Martin, 1891; Ramón y Cajal, 1911/2007) por la prioridad en la formulación de la ley de la polarización dinámica (polémica que en el capítulo octavo de la segunda parte de sus Recuerdos de mi vida llama el histólogo aragonés humildemente "colaboración"), Cajal depura su hipótesis matizando en el artículo de 1897 la primera formulación de 1891 -según la cual el impulso nervioso sigue un trayecto que va desde las dendritas al soma y de éste al axón- al apuntar que el paso del impulso nervioso por el soma no es un hecho universal, sino que en determinadas células no se produce, transcurriendo directamente de la dendrita hacia el axón. Posteriormente, Gray (Gray, 1959) desmentiría la concepción cajaliana vigente acerca del carecer trasmisor-presináptico de todo axón y receptor-postsináptico de toda dendrita. Para una serie de matizaciones y excepciones a la naturaleza de la comunicación nerviosa propuesta por Cajal consúltese Shepherd (1972), y para una perspectiva actual de dichas matizaciones y excepciones Fields (2006).

27. González Recio (2007) ofrece, de forma igualmente sucinta, otras claves para una lectura lakatosiana de la formulación de la ley de la polarización dinámica.

28. Una parte nada desdeñable de la labor desarrollada por Cajal en su estudio del sistema nervioso tendría un impacto fundamental en la investigación del modo en que la actividad neurofisiológica deviene actividad mental, una línea de investigación en la que cabe encuadrar a los seis pesos pesados de las neurociencias a los que acabamos de aludir. No en vano, la producción de Cajal se extiende desde los campos de la neuroanatomía y la neurofisiología hasta el de la neurociencia cognitiva (vid., v. g., Ramón y Cajal, 1895; Ramón y Cajal, 1897; Pérez y Pérez, 1991, especialmente pp. 481 y ss.). "Conocer el cerebro -dejó dicho Cajal- equivale a averiguar el cauce material del pensamiento y de la voluntad" (Ramón y Cajal, 1917/1923/2006, p. 384). No es de extrañar que la labor de Cajal se extendiera hacia la entonces innominada área de la neurociencia cognitiva: ya en una desgraciadamente perdida novela de juventud, Cajal presenta a su protagonista viajando hacia el cerebro humano para sorprender en él al secreto del pensamiento (Albarracín Teulón, 1997, p. 179); después, ya catedrático en Valencia, fundará un Comité de Investigaciones Psicológicas con la intención de indagar acerca de algunos fenómenos curiosos entonces en boga, como la hipnosis, el sonambulismo artificial o la sugestión.

29. El capítulo séptimo de Ramón y Cajal (1899/1913/2008) constituye un importante punto de referencia a este respecto.

30. Ya el propio orden de la marcha de la investigación científica propuesto en el capítulo al que nos referíamos en la nota al pie anterior (observación, experimentación, hipótesis, comprobación) invita a pensar en la concepción de Cajal de la metodología científica en estos términos. 


\section{BIBLIOGRAFÍA}

Albarracín Teulón, Agustín (1997), “Ramón y Cajal. Explorador de selvas vírgenes", Anales del Seminario de Historia de la Filosofía, 14, pp. 171-183.

Albright, Thomas; Jessell, Thomas; Kandel, Eric y Posner, Michael (2000), "Neural science: A century of progress and the mysteries that remain", Cell, 100, Neuron, 25, pp. 1-55.

Alonso, José Ramón (1994), Los métodos de Golgi, Salamanca, Ediciones Universidad de Salamanca.

Apáthy, István (1897), “Das leitende Element des Nervensystems und seine topographischen Beziehungen zu den ZeIlen", Mitteilungen aus der Zoologischen Station zu Neapel, 12, pp. 495-748.

Baratas Díaz, Luis Alfredo (1997), "La obra neuro-embriológica de Santiago Ramón y Cajal", DYNAMIS. Acta Hispanica ad Medicinae Scientiarumque Historiam Illustrandam, 17, pp. 259-279.

Bennett, Miachael (2002), "Neoreticularism and neuronal polarization", Progress in Brain Research, 136, pp. 189-201.

Berlucchi, Giovanni y Buchtel, Henry (2009), "Neuronal plasticity: historical roots and evolution of meaning", Experimental Brain Research, 192 (3), pp. 307-319.

Bethe, Albrecht (1901), "Über die Regeneration periferischen Nerven", Archiv fur Psychiatrie und Nervenkrankheiten, 34, pp. 1066-1073.

Brodal, Alf (1948/1969), Neurological Anatomy in Relation to Clinical Medicine, 2nd ed, New York, Oxford University Press.

Chóliz Montañés, Mariano (1992), “Aportaciones de Ramón y Cajal a la neuropsicología de Donnald O. Hebb", Revista de historia de la psicología, 13 (2-3), pp. 271-276.

Clarke, Edwin y O'Malley, Charles (1996), The Human Brain and Spinal Cord: A Historical Study Illustrated by Writings from Antiquity to the Twentieth Century, $2^{\text {nd }}$ ed., San Francisco, Norman Publishing.

Cowan, William Maxwell y Kandel, Eric (2001), "A brief history of synapses and synaptic transmision". En: Cowan, William Maxwell; Südhof, Thomas; Stevens, Charles (eds.), Synapses, Baltimore, John Hopkins University Press, pp. 1-87.

De Felipe, Javier (2007a), "Cajal y la neurociencia del siglo XXI". En: De Felipe, Javier; Markram, Henry; Wagensberg, Jorge (coords.), Paisajes neuronales: Homenaje a Santiago Ramón y Cajal, Madrid, CSIC, pp. 41-97.

De Felipe, Javier (2007b), “Historia de la neurona: Influencia de los estudios de Santiago Ramón y Cajal en la neurociencia moderna". En: Ramón y Cajal, Santiago, Histología del sistema nervioso del hombre y de los vertebrados, Madrid, Ministerio de Sanidad y Consumo, CSIC, pp. 19-99.
Deiters, Otto Friedrich Karl (1865), Untersuchungen über Gehirn und Rückenmark des Menschen und der Säugethiere, Braunschweig, Vieweg.

Durán Muñoz, García y Alonso Burón, Francisco (1983), Cajal. Vida y Obra, Barcelona, Editorial Científico Médica.

Estañol, Bruno (2007), "El misterio del genio creativo de Santiago Ramón y Cajal. A los 100 años del Premio Nobel”, Salud Mental, 30 (3), pp. 76-80.

Fernández Santarén, Juan Antonio (2014), Santiago Ramón y Cajal: Epistolario, Madrid, La Esfera de los Libros/Fundación Ignacio Larramendi.

Fields, Douglas R. (2006), "Beyond the neuron doctrine", Scientific American Mind, 17 (3), pp. 21-27.

Finger, Stanley (1994), Origins of Neurosciences. A History of Explorations into Brain Function, New York, Oxford University Press.

Finger, Stanley (2000), Minds Behind The Brain: A History Of The Pioneers And Their Discoveries, New York, Oxford University Press.

Forel, Auguste-Henri (1887), "Einige hirnanatomische Betrachtungen und Ergebnisse", Archiv für Psychiatrie und Nervenkrankheiten, 18 (1), pp. 162-198.

García Segura, Luis Miguel (2005), “Ramón y Cajal y la neurociencia del siglo XXI", Jano, 1583, 16-22.

Gerlach, Joseph (1871), "Von dem Rückenmark". En: Stricker, Salomon (ed.), Handbuch der Lehre der Gewebe des Menschen und der Thiere, Leipzig, Engelmann, pp. 665-693.

Gerlach, Joseph (1872), "The spinal cord”. En: Stricker, Salomon (ed.), Manual of Histology, New York, Williams \& Wood, pp. 327-366.

Glickstein, Mitch (2006), “Golgi and Cajal: The neuron doctrine and the 100th anniversary of the 1906 Nobel Prize", Current Biology, 16 (5), pp. 147-151.

Golgi, Camilo (1906), "Neuron doctrine: Theory and facts". En: Lindsten, Jan (ed.), Nobel Lectures, Physiology or Medicine (1901-1921), Amsterdam, Elsevier, pp. 189-217.

González Recio, José Luis (2007), “Ariadna's thread in the labyrinth of nerve action or Santiago Ramón y Cajal's law of dynamic polarisation", Ludus Vitalis, 27, pp. 17-36.

Gray, Edwar (1959), "Axosomatic and axodendritic synapses in the cerebral cortex: An electron microscope study", Journal of Anatomy, 93, pp. 420-433.

Guillery, Rainer (2005), "Observations of synaptic structures: origins of the neuron doctrine and its current status", Philosophical Transactions of Royal Society B, 360, pp. 1281-1307. 
Held, Hans (1897), "Beiträge zur Struktur der Nervenzellen und ihrer Fortsätze. Zweite Abhandlung", Archiv für Anatomie und Physiogie, 21, pp. 204-294.

Jacobson, Marcus (1993), Foundations of Neuroscience, New York, Plenum.

Jones, Edward (1994), "Foundations of neuroscience: by Marcus Jacobson", Trends in Neuroscience, 17 (12), pp. 543-545.

Kölliker, Rudolph Albert (1867), Handbuch der Gewebelehre des Menschen. Für Ärzte und Studirende, Leipzig, Engelmann.

Krause, Johann Friedrich Wilhelm (1863), "Über die Endigung der Muskelnerven", Zeitschrift für Rationelle Medizin, 18, pp. 136-160.

Kühne, Wilhelm Friedrich (1862), Über die peripherischen Endorgane der motorischen Nerven, Leipzig, Engelmann.

Laín Entralgo, Pedro (1978), "Cajal, por sus cuatro costados". En: Ministerio de Educación y Ciencias (ed.) Expedientes administrativos de grandes españoles. II. Santiago Ramón y Cajal, Madrid, Servicio de Publicaciones del Ministerio de Educación y Ciencia, pp. 17-65.

Lakatos, Imre (1978), The Methodology of Scientific Research Programmes, New York, Cambridge University Press.

Llinás, Rodolfo (2003), "The contribution of Santiago Ramón y Cajal to functional neuroscience", Nature Reviews Neuroscience, 4, pp. 77-80.

Lopera Chaves, Marta Cecilia (2008), Estudio de la correspondencia científica de Santiago Ramón y Cajal, Sevilla, Universidad Pablo de Olavide.

López Piñero, José María (1986), “Cajal y la estructura del sistema nervioso", Boletín Informativo. Fundación Juan March, 162, pp. 3-22.

López Piñero, José María (2006), Santiago Ramón y Cajal, Valencia, Publicacions Universitat de València.

Pérez y Pérez, Dionisio (1991), “D. Santiago Ramón y Cajal y las neurociencias", Psicothema, 3 (2), pp. 469-493.

Puelles López, Luis V. (2009), "Contributions to Neuroembryology of Santiago Ramon y Cajal (1852-1934) and Jorge F. Tello (1880-1958)", International Journal of Developmental Biology, 53 (8-10), pp. 1145-1160.

Ramón y Cajal, Santiago (1888a), "Estructura de los centros nerviosos de las aves", Revista Trimestral de Histología Normal y Patológica, 1, pp. 1-10.

Ramón y Cajal, Santiago (1888b), "Sobre las fibras nerviosas de la capa molecular del cerebelo", Revista Trimestral de Histología Normal y Patológica, 2, pp. 33-49.

Ramón y Cajal, Santiago (1889a), "Estructura del lóbulo óptico de las aves y origen de los nervios ópticos", Revista Trimestral de Histología Normal y Patológica, 3, pp. 65-78.
Ramón y Cajal, Santiago (1889b), “Contribución al estudio de la estructura de la médula espinal", Revista Trimestral de Histología Normal y Patológica, 3, pp. 79-106.

Ramón y Cajal, Santiago (1889c), "Conexión general de los elementos nerviosos", La Medicina Práctica, 88, pp. 341-346. (Reimpreso en: Ramón y Cajal, Santiago (2006), Trabajos escogidos 1880-1890, Barcelona, Antoni Bosch, pp. 479-488).

Ramón y Cajal, Santiago (1891), “Comunicación acerca de la significación fisiológica de las prolongaciones protoplásmicas y nerviosas de las células de la sustancia gris", Revista de Ciencias Médicas de Barcelona, 17, pp. 671-679/715-723.

Ramón y Cajal, Santiago (1892), "La rétine des vertébrés", La Cellule, 9, pp. 119-257.

Ramón y Cajal, Santiago (1894), "La fine structure des centres nerveux", Proceedings of the Croonian Lecture at The Royal Society, 55, pp. 444-467.

Ramón y Cajal, Santiago (1895), "Algunas conjeturas sobre el mecanismo anatómico de la ideación, asociación y atención", Revista de Medicina y Cirugía Prácticas, 36, pp. 497-508.

Ramón y Cajal, Santiago (1897), "Leyes de la morfología y dinamismo de las células nerviosas", Revista Trimestral de Micrografía, 2, pp. 1-12.

Ramón y Cajal, Santiago (1899), Textura del sistema nervioso del hombre y de los vertebrados, Madrid, Vidal Leuka.

Ramón y Cajal, Santiago (1899/1913/2008), Reglas y consejos sobre investigación cientifica. Los tónicos de la voluntad, Madrid, Espasa Calpe.

Ramón y Cajal, Santiago (1905), "Sobre la degeneración y regeneración de los nervios", Boletín del Instituto de Sueroterapia, Vacunación y Bacteriología de Alfonso XIII, 1, pp. 49-60/113-119.

Ramón y Cajal, Santiago (1906), "Mecanismo de la regeneración de los nervios", Trabajos del Laboratorio de Investigaciones Biológicas, 4 (3), pp. 119-210.

Ramón y Cajal, Santiago (1911/2007), Histología del sistema nervioso del hombre y de los vertebrados, Madrid, Ministerio de Sanidad y Consumo, CSIC.

Ramón y Cajal, Santiago (1917/1923/2006), Recuerdos de mi vida, Barcelona, Crítica.

Ramón y Cajal, Santiago (1933), “¿Neuronismo o Reticularismo? Las pruebas objetivas de la unidad anatómica de las células nerviosas", Archivos de Neurobiología, 13, pp. 217291/579-646.

Ramón y Cajal, Santiago (1935), "Die Neuronenlehre". En: Bumke, Oswald y Foerster, Otfrid (eds.), Handbuch der Neurologie, vol. I, Berlin, Springer, pp. 887-994. 
Reinoso Suárez, Fernando (1988), "Foreword". En: De Felipe, Javier y Jones, Edward (eds.), Cajal on the Cerebral Cortex, New York, Oxford University Press, pp. VII-IX.

Reinoso Suárez, Fernando (2002), “Cajal hoy: la permanencia de un genio", Revista Española de Patología, 35 (4), pp. 373-384.

Shepherd, Gordon (1972), "The neuron doctrine: A revision of functional concepts", Yale Journal of Biology and Medicine, 45, pp. 584-599.

Shepherd, Gordon (1991), Foundations of the Neuron Doctrine, New York, Oxford University Press.

Sherrington, Charles Scott (1897), "The central nervous system". En: Foster, Michael (ed.), A Text-Book of Physiology, 7th ed., pt. III, London, Macmillan, pp. 928-929.

Swanson, Larry (2003), "The architecture of nervous system". En: Squire, Larry; Bloom, Floyd; McConnell, Susan; Roberts, James; Spitzer, Nicholas; Zigmond, Michael (eds.), Fundamental Neuroscience, $2^{\text {nd }}$ ed., New York, Academic Press, pp. 15-45.
Tanzi, Eugenio (1898), "Sulle modificazione morfologiche funzionali dei dendtriti delle cellule nervose", Rivista di Patologia Nervosa e Mentale, 3, pp. 337-359.

Toledano, Adolfo (1983), “Cajal's studies on developing cerebeIlum. Their relations to modern findings on postnatal cerebellar circuitry". En: Grisolía, Santiago; Guerri, Chelo; Samson, Féré; Norton, Stata; Reinoso-Suarez, Fernando (eds.), Ramón y Cajal's Contribution to the Neurosciences, New York, Elsevier, pp. 125-135.

Van der Loos, Hendrik (1967), "The history of the neuron". En: Hyden, Holger (ed.), The neuron, Amsterdam, Elsevier, pp. 1-47.

Van Gehuchten, Arthur (1891), "La structure des centres nerveux. La moelle épinière et le cervelet", La Cellule, 7, pp. 79-122.

Van Gehuchten, Arthur y Martin, Is (1891), "Le bulbe olfactif chez quelques mammiféres”, La Cellule, 7, pp. 205-237. 